\title{
Energia e futuro
}

\section{David Zjlberstein}

O planejamento energético mundial pautou-se, ao longo de décadas, por uma lógica de atrelamento inexorável entre o crescimento da demanda energética e o desenvolvimento econômico. Desta maneira, o futuro da demanda de energia a ser atendida nada mais seria do que uma mera extensão do passado, bastando para isso lançar mão de uma das inúmeras correlações econométricas energia-PIB existentes, e extrapolá-la para o futuro. Esta premissa prevaleceu principalmente durante os períodos de farta abundância e de preços irrisórios da oferta de energia. Apesar dos dois choques do petróleo, o planeta continua a consumir energia de maneira extremamente desequilibrada, onde apenas $15 \%$ da população mundial consome quase $50 \%$ de toda a energia atualmente disponível. Em outros termos, as enormes carências energéticas dos países em desenvolvimento confrontam-se com os grandes desperdícios dos países desenvolvidos, gerando perturbações cada vez mais importantes nas relações entre as regiões do mundo.

A proposta de Energy for a sustainable world rompe de modo inequívoco com esta lógica, na qual a satisfação das necessidades das sociedades humanas poderiam ser atendidas, em termos energéticos, ad infinitum, ignorando-se os efeitos indiretos da utilização abusiva e incontrolada de energia. O livro derruba diversos "mitos" do planejamento energético convencional, que, à semelhança do planejamento econômico tradicional, reluta em internalizar em suas análises os efeitos que não contribuam, segundo a otica do planejador, com o ótimo desejado.

Esses efeitos, considerando-se a sua vertente política e social, funcionam como elemento impeditivo a um efetivo esforço de desenvolvimento dos países mais pobres, visto o papel decisivo e indispensável representado pela disponibilidade de energia em qualquer que seja a proposta. Nestes países, essa disponibilidade é fortemente dificultada devido ao acesso limitado às formas de energia mais modernas e mais eficientes (tais como a eletricidade e os derivados de petróleo), e também às tecnologias de uso mais eficientes, implicando num aumento do fosso existente entre estes países e os países ricos. Considerando-se a vertente ambiental (dispensada de grandes apresentações, em virtude da força crescente do movimento ambientalista internacional), pode-se afirmar que o uso de energia é o maior gerador de impactos sobre os ecossistemas terrestres: a emissão de $\mathrm{CO}_{2}$ (causando o efeito estufa), provocada pela queima de combustíveis fósseis (essencialmente petróleo e carvão mineral); as chuvas ácidas provocadas pelas emissões de $\mathrm{SO}_{2}$ e $\mathrm{NOx}$ (dióxido de enxofre e óxidos de nitrogênio, também provocados pelos combustíveis fósseis, principalmente a partir de termoelétricas) e que causam a morte de florestas, lagos e rios, e a destruição do patrimônio das cidades; os grandes projetos hidroelétricos, inundando vastas áreas e acarretando a destruição de zonas férteis, expulsando populações e alterando as características da fauna e da flora locais; a destruição indiscriminada de florestas para produção de carvão vegetal ou para cozimento de alimentos, implicando também na produção de $\mathrm{CO}_{2}$, na desertificação e na erosão das áreas atingidas; as termoelétricas de origem nuclear que, além dos riscos in-
DAVID ZJLBERSTEIN é coordenador do curso de Pós-Graduaçăo em Energia da USP.

Energy for a sustainable world. Goldemberg, Johansson, Reddy e Williams. Nova Delhi, Editora Wiley Easten Limited, 1988. 


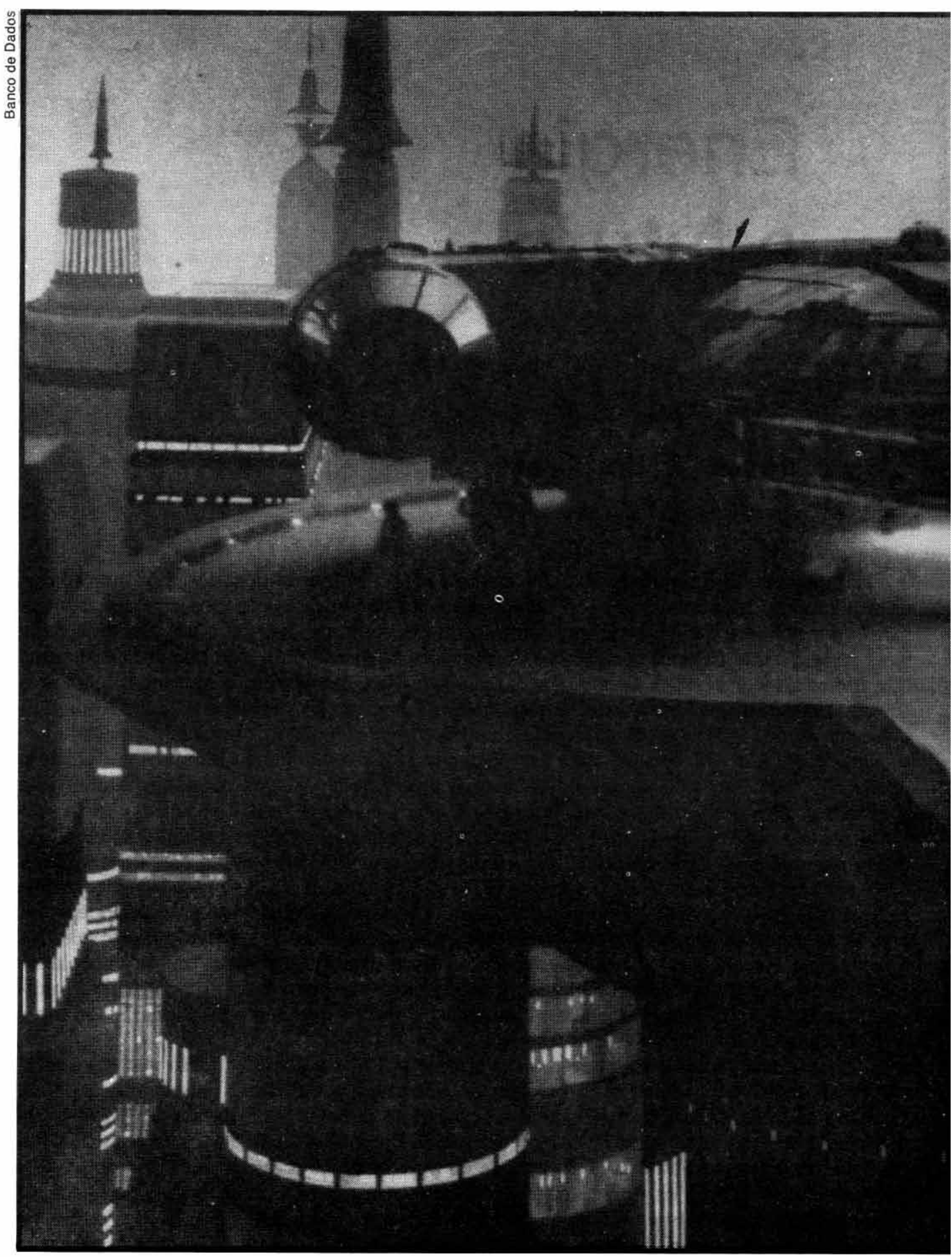

$O$ futuro e o passado. Na foto maior, a nave Milenium Falcon de Han Solo (Harrison Ford) chega a Cloud Clty (Cidade das Nuvens)

em Guerra nas estrelas 2; à direita, a máquina a vapor de James Watt, 1788

trínsecos ao seu funcionamento, acarretam a existência de rejeitos altamente radioativos, potencialmente propensos à fabricação de artefatos nucleares (como é o caso do plutônio) e que têm, em alguns casos, um período de radioatividade superior a dois milhões de anos; os derramamentos de quantidades cada vez maiores de óleo de grandes petroleiros, causando verdadeiras catástrofes ecológicas.

O livro, resultado do feliz encontro de quatro pesquisadores, oriundos de quatro diferentes continentes (Goldemberg é brasileiro, Johansson, sueco, Reddy, indiano, e Williams, americano), trata a questão energética de forma vinculada ao atendimento das necessidades básicas da humanidade, levando-se em consideração um elenco de medidas voltadas a um desenvolvimento equilibrado, seguro, eficiente economicamente e em harmonia com o meio ambiente.

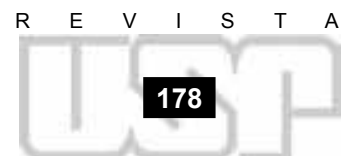

Setembro

Outubro

Novembro

1990 


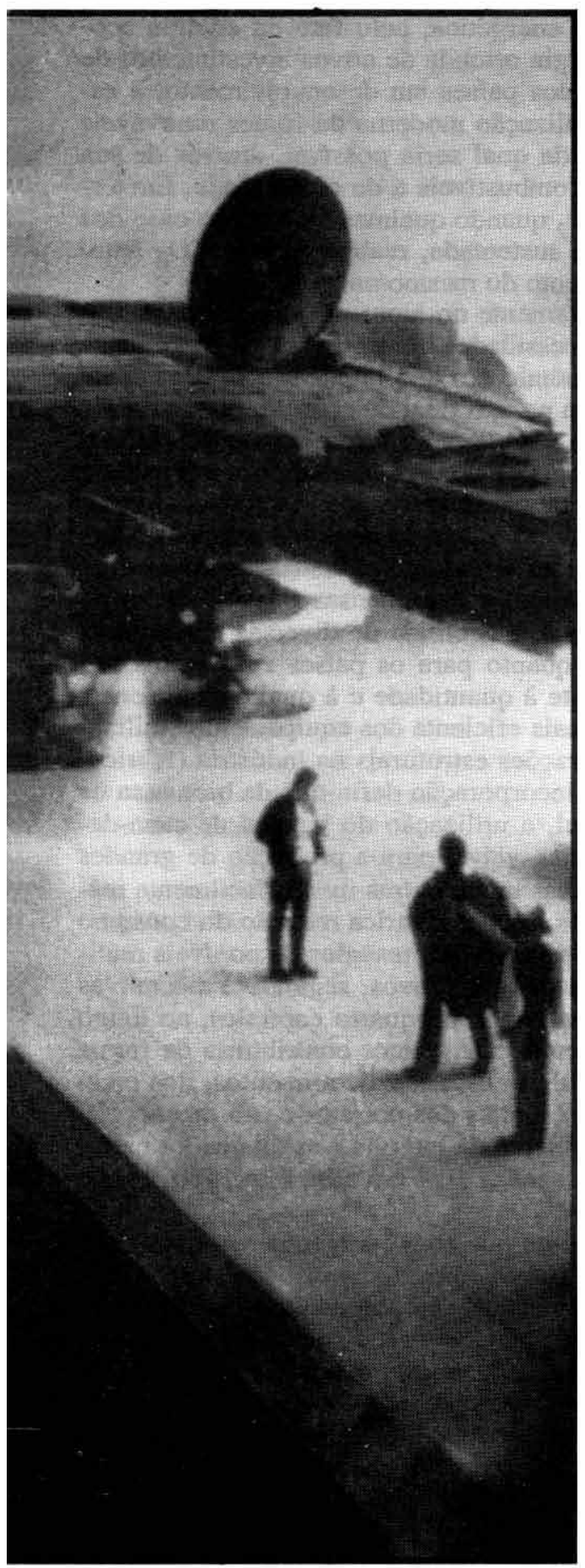

O livro, resultado do

feliz encontro de quatro

pesquisadores,

oriundos de quatro

continentes (Goldemberg

é brasileiro, Johansson,

sueco, Reddy, indiano e

Williams, americano),

trata da questão

energética de forma vinculada

ao atendimento

das necessidades básicas

da humanidade em

consideração ao elenco

de medidas voltadas

a um desenvolvimento

equilibrado, seguro, eficiente economicamente

e em harmonia com o ambiente

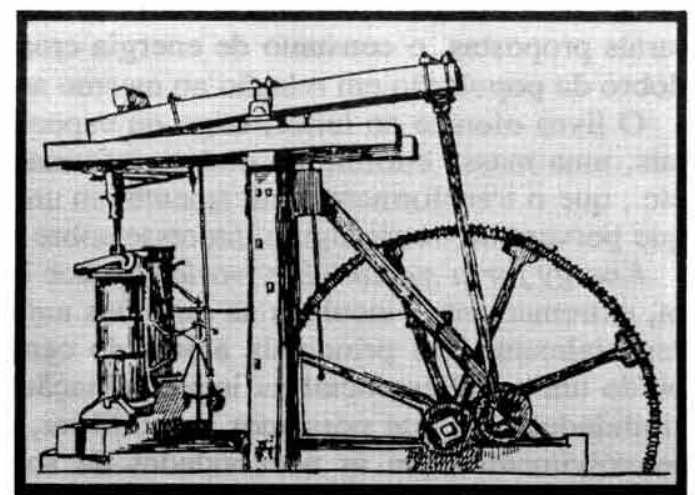

Inicialmente, o livro percorre, em termos gerais, os padrōes de consumo de energia necessários à consecução dos objetivos acima (a título ilustrativo, é apresentada a previsão de um dos órgãos que tradicionalmente produzem previsões de demanda de energia. Caso estas previsões se confirmassem, para que a demanda mundial de energia, no ano 2030, fosse satisfeita, seria necessária a construção de uma central nuclear de 1 GW, a partir de 1975 , a cada quatro a seis dias, ou o equivalente a uma Itaipu a cada sessenta dias, aproximadamente!). Em seguida, desenvolve-se, separadamente, para os países desenvolvidos e para os países em desenvolvimento, as estratégias energéticas em conformidade com os mesmos princípios. No caso dos países desenvolvidos é ressaltado o câmbio estrutural vivido pelos mesmos, no sentido de abandonarem progressivamente a produção de bens que requeiram um alto teor de energia. A estratégia mais

Setembro 
relevante implicaria no incremento da eficiência energética, pelo fato da energia economizada ser cada vez mais barata do que a energia oriunda de novos investimentos de expansão do sistema de fornecimento. No caso dos paŕses em desenvolvimento, a estratégia principal implicaria um incremento da utilização moderna de fontes renováveis de energia, especialmente a bioenergia, a partir da qual seria possível, através de sua transformação, dispor-se de uma vasta gama de combustíveis e de eletricidade. Em termos ecológicos, a biomassa, apesar de emitir $\mathrm{CO}_{2}$ quando queimada, como no caso dos combustíveis fósseis, usada de forma racional e sustentada, reabsorveria o $\mathrm{CO}_{2}$ anteriormente emitido, evitando dessa maneira o aumento do mesmo na atmosfera.

O caráter mais inovador da obra aparece exatamente no momento da análise da demanda de energia necessária à satisfação das necessidades humanas, não mais baseada em extrapolações associadas ao crescimento econômico (o que implicaria simplesmente em investimentos de expansão da oferta), mas sim no uso final de energia, ou em outros termos, baseada num processo de conhecimento e de gestão desta demanda. Daŕ em diante, o livro é um verdadeiro manancial de opções aos atuais padrões propostos a partir das previsões de demanda e características de consumo de energia convencionais. No caso espećffico do Brasil (que participa do livro através de diversos exemplos), em virtude de sua característica de pars que conta com um tecido industrial relativamente importante (e mesmo competitivo em alguns setores) e das imensas possibilidades de utilização moderna de fontes renováveis de energia, a acolhida de diversas alternativas propostas no texto, tanto para os países ricos, quanto para os países em desenvolvimento, implicaria um salto significativo no tocante à quantidade e à qualidade da energia consumida. A conservação de energia (uso mais eficiente dos equipamentos utilizadores e incorporação de novas tecnologias), alterações estruturais na indústria (fabricação de produtos com menor teor de energia) e a incorporação definitiva da biomassa na produção de energia (além do álcool combustŕvel, a utilização do bagaço de cana-deaçúcar é uma alternativa técnica e economicamente viável para a produção de grandes quantidades de eletricidade). Essas opções, algumas mais, outras menos facilmente materializáveis, implicariam, em termos quantitativos, numa drástrica redução do consumo mundial de energia futuro, se levarmos em consideração as previsões disponf́veis realizadas dentro dos padrões convencionais. Em termos qualitativos, segundo expectativas e cenários dos próprios autores (cenários desenvolvidos no quarto capítulo), ao longo dos próximos trinta anos, a resolução dos problemas energéticos contribuiria de forma decisiva para a solução das disparidades norte-sul, da escassez de alimentos, dos crescentes e cada vez mais preocupantes impactos ambientais dos projetos e uso da energia. No mundo, em 2020, através de um uso mais eficiente da energia e as alterações estruturais propostas, o consumo de energia cresceria apenas $10 \%$ em relação a 1980 , com o dobro da população em relação ao mesmo ano.

O livro oferece ao leitor, leigo ou especialista em questões energéticas e/ou ambientais, uma massa enorme de dados, informações, referências, notas isoladas, apêndices, etc., que o transformam praticamente em um handbook de referência a todo(a) aquele(a) que porventura nutrir algum interesse sobre questões energéticas e ambientais.

Energy for a sustainable world fornece à sociedade mundial (e à sociedade brasileira, extremamente vinculada às questões ambientais ligadas à problemática energética) e especialmente aos principais atores do cenário decisório internacional, a quem é atri-. bufdo um papel essencial na implementação das ações preconizadas, as pistas e as possibilidades para que possamos reequilibrar, de modo duradouro, as necessidades do desenvolvimento com as necessidades de sobrevivência dos usuários deste desenvolvimento.

Enfim, Energy for a sustainable world, apesar de em algumas de suas passagens carregar suas tintas em possibilidades talvez exageradamente otimistas, é verdadeira inflexão quanto ao planejamento energético mundial, onde a energia não mais resume-se ao atendimento de certos confortos (iluminação, transporte, comunicações, etc.), mas é também, ao mesmo tempo, fator de grandes riscos para as gerações presentes e futuras. Esses riscos, em função de suas características globais, não privilegiam ou poupam alguns paŕses ou regiões. Ao contrário, sua abrangência incita e exige compromisso amplo de cooperação entre os parses desenvolvidos e em desenvolvimento. Está em jogo, em termos claros e duros, o futuro que teremos, ou que pelo menos gostariamos de ter. 